\title{
A Simple Formula to Estimate Parathyroid Weight on 4D-CT, Predict Pathologic Weight, and Diagnose Parathyroid Adenoma in Patients with Primary Hyperparathyroidism
}

\author{
(D) R. Yeh, (D).-K.D. Tay, (DL. Dercle, (D) L. Bandeira, (DM.R. Parekh, and (D).P. Bilezikian
}

\begin{abstract}
BACKGROUND AND PURPOSE: Parathyroid gland weight is a clinically relevant parameter used to diagnose parathyroid adenomas intraoperatively. We evaluated the accuracy of a formula to estimate parathyroid weight on preoperative 4D-CT.

MATERIALS AND METHODS: A single-institution retrospective study was performed in patients with primary hyperparathyroidism who underwent 4D-CT between January 2013 and December 2014 with subsequent parathyroidectomy and surgical cure. All patients had correct localization of a solitary parathyroid adenoma. The longest 3 dimensions of all identified parathyroid glands were measured on CT, and weight was estimated using the formula: weight ${ }_{4 \mathrm{D}-\mathrm{CT}}(\mathrm{mg})=1 \mathrm{mg} / \mathrm{mm}^{3} \times$ Length $(\mathrm{mm}) \times$ Width $(\mathrm{mm}) \times$

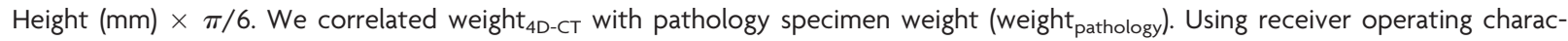
teristic analysis, we estimated the performance of weight $4 \mathrm{D}-\mathrm{CT}$ to discriminate a parathyroid adenoma from normal glands on 4DCT and determined the optimal threshold based on the Youden index.
\end{abstract}

RESULTS: One hundred sixteen patients (85 women, $31 \mathrm{men}$ ) were evaluated. Weight ${ }_{4 \mathrm{D}-\mathrm{CT}}$ was shown to be strongly correlated with weight $_{\text {pathology }}$ as demonstrated by Spearman $\rho=0.73(P<.01)$, concordance correlation coefficient $=0.92(95 \% \mathrm{Cl}$, 0.89-0.94), and Cronbach $\alpha=0.96$. The performance of weight ${ }_{4 \mathrm{D}-\mathrm{CT}}$ for the diagnosis of parathyroid adenoma was excellent, with an area under the curve of $0.955(95 \% \mathrm{Cl}, 0.925-0.985 ; P<.001)$. Based on the Youden index, the optimal threshold was $>50 \mathrm{mg}$, with a sensitivity of $96.7 \%$ and a specificity of $95.7 \%$.

CONCLUSIONS: Radiologists can accurately estimate parathyroid adenoma weight on 4D-CT. This metric is highly correlated with pathologic weight, and a threshold cutoff of $>50 \mathrm{mg}$ can be used to distinguish parathyroid adenoma from normal glands.

ABBREVIATIONS: AUC = area under the curve; IQR = interquartile range; $\mathrm{ROC}=$ receiver operating characteristic

arathyroid 4D-CT is a relatively new imaging technique for preoperative localization of parathyroid adenomas in patients with primary hyperparathyroidism. First reported by Rodgers et $\mathrm{al}^{1}{ }^{1}$ in 2006, 4D-CT has increasingly gained acceptance, most commonly as a second-line approach to the traditional methods of nuclear

\section{Received February 17, 2020; accepted after revision June 2}

From the Department of Radiology (R.Y.), Molecular Imaging and Therapy Service, Memorial Sloan Kettering Cancer Center, New York, New York; Department of Endocrinology (Y.-K.D.T.), Sengkang General Hospital, Singhealth, Singapore; Department of Radiology (R.Y., L.D., M.R.P.), New York-Presbyterian Hospital/ Columbia University Medical Center, New York, New York; Department of Endocrinology (L.B.), Federal University of Sao Paulo, Sao Paulo, Brazil; Fleury Group (L.B.), Sao Paulo, Brazil; Department of Radiology (M.R.P.), Thomas Jefferson University Hospital, Philadelphia, Pennsylvania; and Department of Medicine (J.P.B.), Division of Endocrinology, College of Physicians \& Surgeons, Columbia University, New York, New York.

Please address correspondence to Randy Yeh, MD, Department of Radiology, Molecular Imaging and Therapy Service, Memorial Sloan Kettering Cancer Center, 1275 York Ave, New York, NY 10065; e-mail: yehr@mskcc.org scintigraphy and sonography. It has also demonstrated the potential to be used as a first-line parathyroid imaging technique. ${ }^{2}$ Studies have demonstrated a relatively high sensitivity of $4 \mathrm{D}-\mathrm{CT}$ for localization of parathyroid adenomas and hyperplasia, with reported sensitivities ranging from $76 \%$ to $88 \% \%^{1,3,4}$ and superior localization compared with sestamibi and sonography. ${ }^{4-6}$ Accurate preoperative imaging allows surgeons to appropriately select patients for minimally invasive parathyroidectomy by localizing a single parathyroid adenoma and excluding multigland disease. ${ }^{2}$

While identification of parathyroid adenomas by $4 \mathrm{D}-\mathrm{CT}$ relies on their characteristic differential enhancement across time, the classic enhancement pattern is observed in only a minority of adenomas $(20 \%) .^{7}$ In the setting of variable enhancement patterns, gland size may serve as an additional $4 \mathrm{D}-\mathrm{CT}$ parameter for identifying adenomas preoperatively, particularly in distinguishing normal from abnormal glands. This is in line with the intraoperative approach of the parathyroid surgeon, because weight and size are the most frequently used criteria for 


\section{0 patients with PHPT who underwent combined imaging protocol}

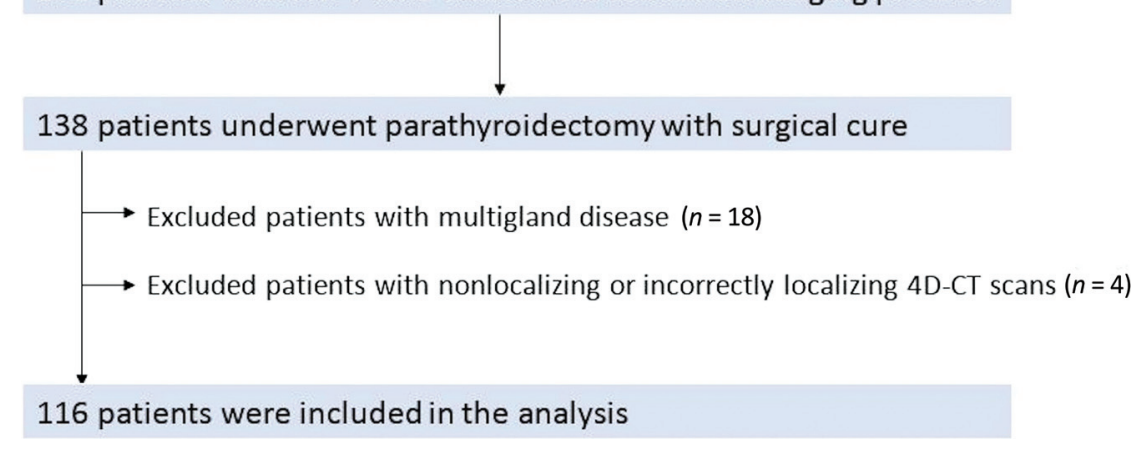

FIG 1. Study flowchart with inclusion and exclusion criteria. PHPT indicates primary hyperparathyroidism.

identifying abnormal glands, with additional intraoperative features including shape, consistency, and histologic features. ${ }^{8}$ The weight of the pathologic specimen is considered to be the best measure of gland size, as opposed to gland length, due to the variable shape of parathyroid glands. ${ }^{9}$ Normal parathyroid glands generally weigh $20-40 \mathrm{mg}$, with glands of $>60 \mathrm{mg}$ usually considered abnormal by pathologists and surgeons. ${ }^{8,10}$

The high spatial resolution of 4D-CT allows delineation of adenomas from adjacent structures, which in theory, would allow an accurate estimate of adenoma size. While a pathologic size threshold may be inferred to $4 \mathrm{D}-\mathrm{CT}$, several factors may influence such estimates, such as adenoma shape, location, and relationship to and mass effect from adjacent structures, such as an enlarged multinodular thyroid gland or esophagus. These potential confounders do not affect the actual weight of the pathologic specimen following surgical resection. Studies in lung cancer and renal cell carcinoma correlating tumor sizes as measured on CT scans with pathologic specimens have shown poor correlation, with statistically significant differences in measured size on CT compared with pathologic size. ${ }^{11,12}$

Differential contrast enhancement remains the dominant factor in the detection of parathyroid adenomas, but a potential role for estimated adenoma weight by preoperative 4D-CT has not been evaluated. The size cutoff on 4D-CT to distinguish a normal gland from an adenomatous gland remains unknown. The aims of our study were to correlate the estimated gland weight of parathyroid adenoma on 4D-CT with the weight of the pathologically resected adenoma in patients with primary hyperparathyroidism and single-gland disease and to determine whether 4D-CT can define a threshold weight that distinguishes a normal gland from an adenomatous gland. We hypothesized that estimating weight on $4 \mathrm{D}-\mathrm{CT}$ using a predefined formula will have a strong correlation with pathologic weight, and a threshold CT weight cutoff can differentiate adenomas from normal glands.

\section{MATERIALS AND METHODS Patients}

A retrospective review was conducted of 250 consecutive patients with biochemical evidence of primary hyperparathyroidism referred to our institution for preoperative imaging using a combined imaging protocol of $4 \mathrm{D}-\mathrm{CT}$ and sestamibi
SPECT/CT between January 2013 and December 2014. Of note, an analysis of the diagnostic performance of this combined imaging protocol has been previously published by our group, ${ }^{6}$ and there is some overlap of patients from that study with patients in this cohort. Figure 1 summarizes the study patient flow. Of 250 patients, 138 patients underwent parathyroidectomy with surgical cure, defined by a $50 \%$ drop in intraoperative parathyroid hormone levels into the normal range. Intraoperative parathyroid hormone monitoring has been shown to have excellent accuracy in predicting surgical cure and is recommended by the Endocrine Society Guidelines. ${ }^{13,14}$ Most patients ( $n=90$ patients) had intraoperative parathyroid hormone normalization within 10 minutes of adenoma resection. Twenty-two patients were excluded for the following reasons: Eighteen patients had multigland disease, and 4 patients had nonlocalization or incorrect localization on 4D-CT. The remaining 116 patients with solitary adenoma correctly localized on $4 \mathrm{D}$-CT were used for this analysis.

The study did not include patients in whom 4D-CT did not correctly localize the culprit solitary adenoma (3.3\%, $n=4 / 120)$ with a mean adenoma pathologic weight of $136 \mathrm{mg}$. The reason for not including these individuals is that this was a correlation analysis of weight estimated on 4D-CT and pathologic specimen weight. The intention of the study was also to discriminate between the weights of normal and abnormal glands on $4 \mathrm{D}-\mathrm{CT}$, thus requiring inclusion only of those individuals with correct localization. This study was Health Insurance Portability and Accountability Act-compliant and approved by the institutional review board at Columbia University Medical Center.

\section{D-CT Imaging Protocol}

The imaging protocol consisted of a combined sestamibi SPECT and $4 \mathrm{D}-\mathrm{CT}$ consecutively acquired in a single setting previously published by our group. ${ }^{6}$ In brief, the protocol consists of a dualphase technetium Tc99m sestamibi SPECT, followed by a 4D-CT performed immediately after acquisition of the delayed phase sestamibi SPECT/CT. For the purposes of this study, only the $4 \mathrm{D}$ CT protocol will be discussed. All imaging was performed with a Symbia T 16-slice SPECT/CT scanner (Siemens).

The $4 \mathrm{D}-\mathrm{CT}$ protocol consisted of helical scans acquired in noncontrast, arterial, and delayed (venous) phases at predetermined times. For all phases, scanning parameters were the following: $130 \mathrm{kV}$ (peak), $120-300 \mathrm{~mA}$ by automatic exposure control, 0.6-second rotation time, 0.8 pitch, and 1.0-mm detector configuration with a beam width of $10 \mathrm{~mm}$. Coronal and sagittal reformats were reconstructed with $1-\mathrm{mm}$ section thickness. The FOV extended from the level of the mandibular angle to the carina. Following the noncontrast CT acquisition, iodinated contrast (iohexol, Omnipaque 350; GE Healthcare) was injected at $4 \mathrm{~mL}$ per second with a total dose of $75 \mathrm{~mL}$. The arterial phase 


\begin{tabular}{lc}
\hline \multicolumn{1}{c}{ Parameter Value } & Data \\
\hline Age (yr) & $63 \pm 14(19-89)$ \\
Sex (No. of patients) & $85(73.3 \%)$ \\
Women & $31(26.7 \%)$ \\
Men & $76.4 \pm 19.9(38.1-146)$ \\
Weight (kg) & $28.0 \pm 7.0(16.6-53.7)$ \\
BMI & $101(67.0-135)$ \\
Biochemical profile ${ }^{b}$ & $10.8(10.4-11.4)$ \\
PTH (median) (IQR) $(\mathrm{pg} / \mathrm{mL})^{\mathrm{c}}$ & \\
Calcium (median) $(\mathrm{IQR})(\mathrm{mg} / \mathrm{dL})$ & $310(30-11,218)$ \\
Parathyroid gland weights $(\mathrm{median})($ range) (IQR) & $500(22-9400)$ \\
CT weight, adenoma $(\mathrm{mg})(n=116)$ & $18(4-144)$ \\
Pathology weight, adenoma $(\mathrm{mg})(n=116)$ & \\
CT weight, normal gland $(\mathrm{mg})(n=291)$ & $145-536$ \\
\hline
\end{tabular}

Note:-PTH indicates parathyroid hormone; BMI, body mass index.

${ }^{\text {a }}$ Data are presented as mean \pm SD with ranges or percentages in parentheses.

${ }^{\mathrm{b}}$ Data are presented as median (interquartile range).

${ }^{c}$ Normal ranges for parathyroid hormone and serum calcium are $10-65 \mathrm{pg} / \mathrm{mL}$ and $8.4-10.2 \mathrm{mg} / \mathrm{dL}$, respectively.

CT was acquired 30 seconds after the beginning of contrast infusion, and the delayed phase CT was acquired 30 seconds after the arterial phase acquisition.

\section{Parathyroid Adenoma Localization and CT Estimated Weight}

4D-CT images were interpreted for preoperative localization by 2 radiologists with dual board certification in radiology and nuclear medicine. 4D-CT images were reviewed on a PACS workstation. Parathyroid adenomas and normal parathyroid glands were identified using location and temporal contrast enhancement on serial phases. Following identification, adenoma volume was estimated in cubic millimeters using the formula for ellipsoid volume $(\mathrm{V})$ :

$\mathrm{V}_{4 \mathrm{D}-\mathrm{CT}}\left(\mathrm{mm}^{3}\right)=\mathrm{L}(\mathrm{mm}) \times \mathrm{W}(\mathrm{mm}) \times \mathrm{H}(\mathrm{mm}) \times \pi / 6$.

Using the arterial phase CT, dimensions for length (L) and width (W) were measured on the axial plane in the longest perpendicular dimension, while height $(\mathrm{H})$ was measured on either the coronal or sagittal plane, depending on the plane on which the adenomas were best visualized. Then, adenoma weight was estimated in milligrams by converting volume to weight. To this end, we assumed that all adenomas had the density of water $\left(1 \mathrm{mg} / \mathrm{mm}^{3}\right)$ and used the formula, weight $(\mathrm{W})=$ density $\times$ volume $(\mathrm{V})$.

$$
\mathrm{W}_{4 \mathrm{D}-\mathrm{CT}}(\mathrm{mg})=1 \mathrm{mg} / \mathrm{mm}^{3} \times \mathrm{V}_{\text {adenoma }}\left(\mathrm{mm}^{3}\right) \text {. }
$$

Therefore, the formula used for parathyroid weight on $4 \mathrm{D}-\mathrm{CT}$ (weight $_{4 \mathrm{D}-\mathrm{CT}}$ ) was

Weight $_{4 \text { D-CT }}(\mathrm{mg})=1 \mathrm{mg} / \mathrm{mm}^{3} \times \mathrm{L}(\mathrm{mm}) \times \mathrm{W}(\mathrm{mm}) \times$ $\mathrm{H}(\mathrm{mm}) \times \pi / 6$.

Estimated weights of suspected parathyroid adenomas and any additional visualized normal parathyroid glands were measured and described in the original radiology report, per standard clinical practice at our institution. Both interpreting radiologists were trained on this method for estimating weight on CT. Of the 116 patients, 75 patients had $4 \mathrm{D}-\mathrm{CT}$ scans that identified and estimated CT weights of 3 normal parathyroid glands in addition to the abnormal parathyroid adenoma, 30 patients had 2 normal parathyroid glands identified, 6 patients had 1 normal parathyroid gland identified, and 5 patients had no normal parathyroid glands identified. In total, 407 parathyroid glands (normal, $n=$ 291, and adenomas, $n=116$ ) were identified in 116 patients.

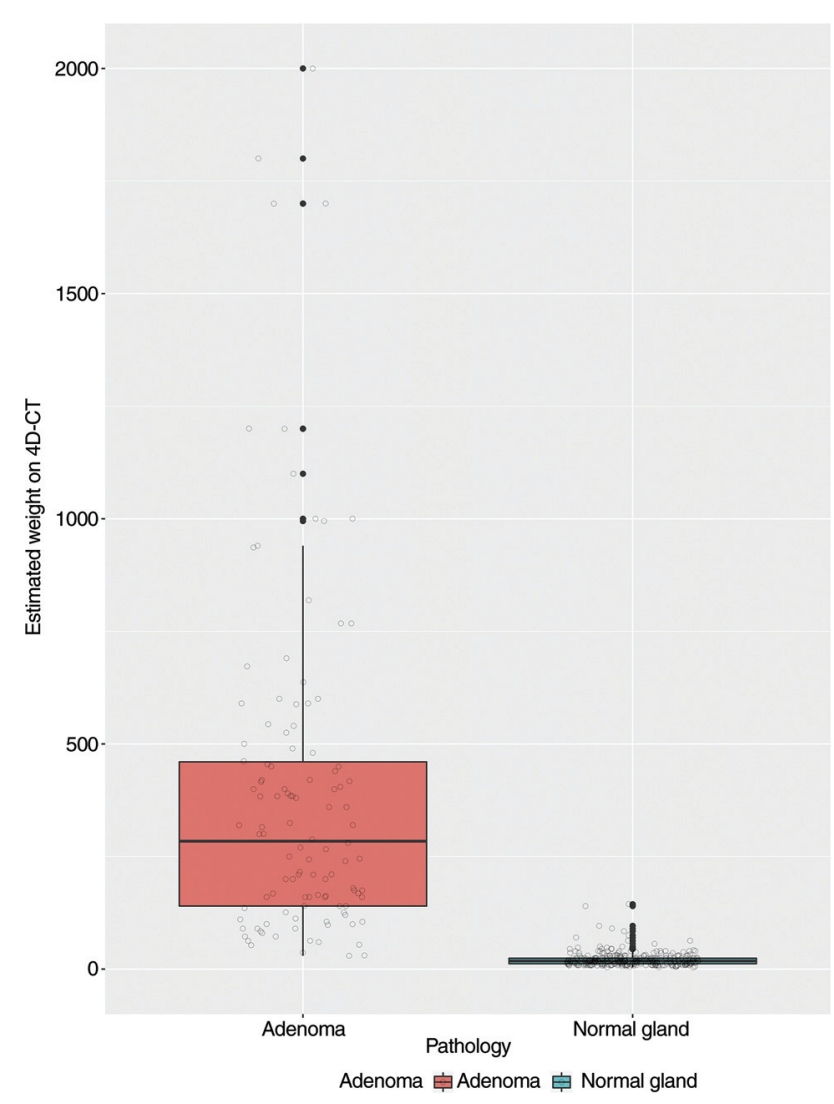

FIG 2. Boxplot of weight ${ }_{4 D-C T}$ in milligrams of parathyroid adenomas compared with normal parathyroid glands.

\section{Pathology}

Surgically resected parathyroid glands were placed in formalin for fixation. Extracapsular fat was dissected off the surgical specimen, when appropriate. The weight (milligrams) of the surgical specimen was recorded. Pathologic examination of the specimen was performed to confirm parathyroid adenoma.

\section{Statistical Analysis}

The radiology, operative, and pathology reports were retrieved from the Electronic Medical Record. CT-estimated weight and 


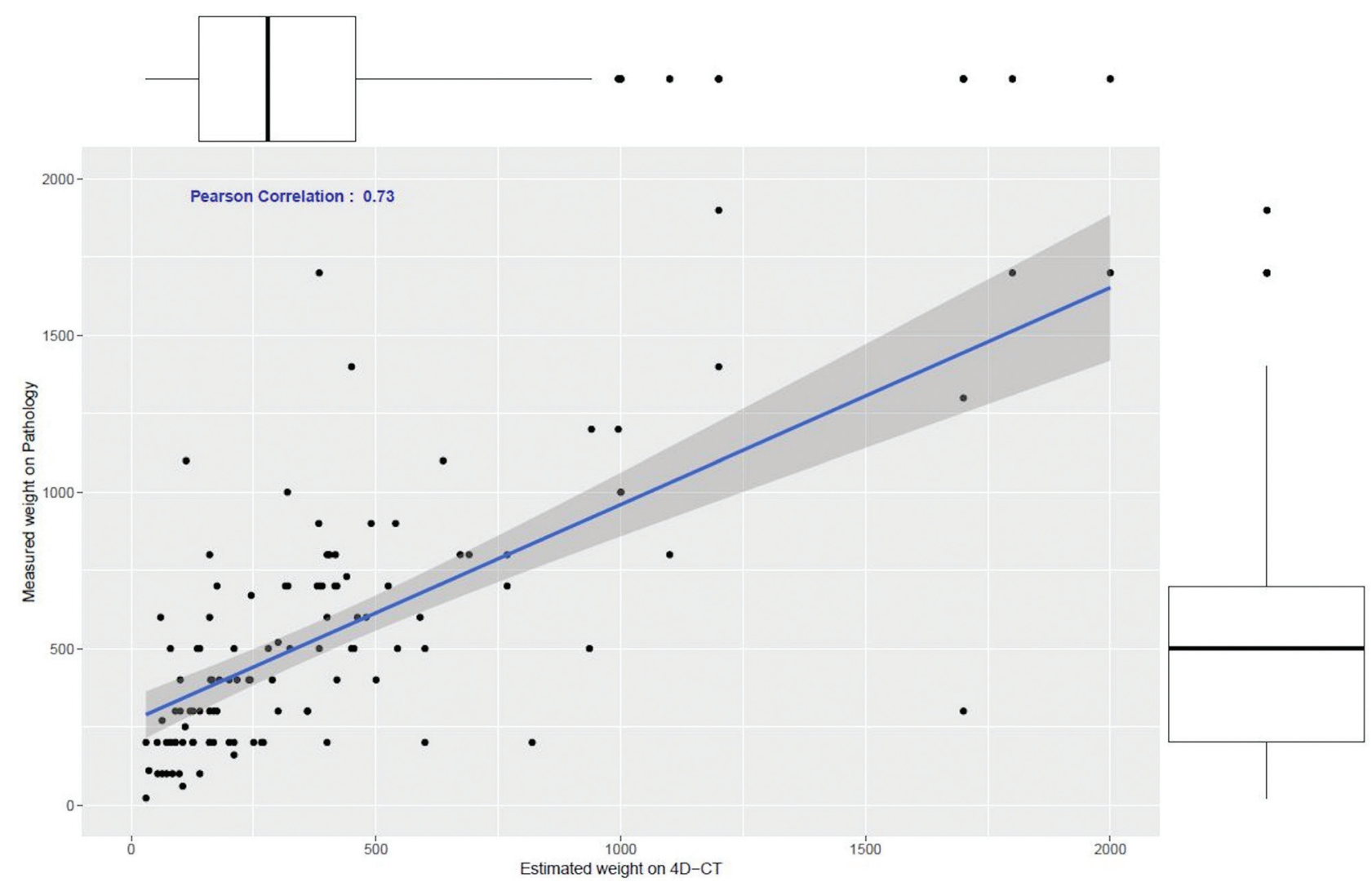

FIG 3. Scatterplot showing the relationship between weight $t_{4 \mathrm{D}-\mathrm{CT}}$ in milligrams of the parathyroid adenoma ( $x$-axis) and the measured pathologic weight of the resected parathyroid adenoma, weight pathology $_{\text {( }}$-axis). The blue line indicates the Pearson correlation $(r=0.73, P<.01)$.

pathologic weight were recorded on the basis of original radiology and pathology reports, respectively, and no re-interpretation or repeat measurements were performed.

Data were assessed for normality by visual inspection of the histograms. Normally distributed data are presented as mean \pm $\mathrm{SD}$, while nonparametric data are presented as median and interquartile range (Q25-Q75). We used 3 metrics to compare CTestimated weight and pathologic weight measurements: the Spearman correlation coefficient, the concordance correlation coefficient, and the Cronbach $\alpha .{ }^{15}$

To determine the weight cutoff for parathyroid adenomas on $4 \mathrm{D}-\mathrm{CT}$, we constructed a receiver operating characteristic (ROC) curve with the normal parathyroid gland or parathyroid adenoma as the state variable and $\mathrm{CT}$-estimated weight as the test variable, and the area under the ROC curve (AUC) and $95 \%$ confidence interval were estimated. Because multiple gland weights were included per patient, ROC analysis incorporating clustering of observations within a patient was performed. The Youden index (sensitivity + specificity -1$)$ was calculated to determine the optimal threshold for CTestimated weight to discriminate a parathyroid adenoma from a normal gland. Using cross-validation analysis, we randomly selected $80 \%$ of the sample for the training set and applied ROC curve analysis to obtain the optimal threshold. We then tested the threshold against the remaining $20 \%$ of the sample for its performance. As an ancillary study, we also evaluated the performance of parathyroid length (millimeters) using the longest single dimension. All statistical tests were 2 -tailed, and $P<.05$ was considered significant. All analyses were performed with SPSS 23.0 for Windows (IBM).

\section{RESULTS}

\section{Patient Characteristics}

Table 1 summarizes the study patient characteristics and parathyroid gland weights. The study population $(n=116)$ was predominantly female $(n=85,73.3 \%)$, with a mean age of $63 \pm 14$ years. Median serum parathyroid hormone and calcium levels were $101 \mathrm{pg} / \mathrm{mL}$ (interquartile range $[\mathrm{IQR}]=67.0-135 \mathrm{pg} / \mathrm{mL}$ ) and $10.8 \mathrm{mg} / \mathrm{dL}(\mathrm{IQR}=10.4-11.4 \mathrm{mg} / \mathrm{dL})$, respectively. Parathyroid adenomas $(n=116)$ had a median CT weight of $310 \mathrm{mg}$ (IQR = $145-536 \mathrm{mg}$ ) and pathologic weight of $500 \mathrm{mg}$ (IQR = 238-800 $\mathrm{mg}$ ), with a mean difference of $130 \mathrm{mg}$ between CT and pathologic weights. Normal parathyroid glands $(n=291)$ had a median CT weight of $18 \mathrm{mg}(\mathrm{IQR}=12-24 \mathrm{mg})$. Figure 2 demonstrates a boxplot of CT weights of parathyroid adenomas compared with normal glands.

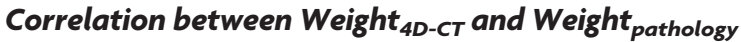

CT-estimated weight had a strong positive correlation with the pathologic adenoma weight $(r=0.73, P<.01)$ (Fig 3$)$. The concordance correlation coefficient between the 2 measurements was 0.92 (95\% CI, 0.89-0.94), showing moderate agreement, and the Cronbach $\alpha$ was measured as 0.96 , demonstrating excellent reliability. A Bland-Altman plot showed good agreement between the estimated weight by CT and the measured pathologic weight 

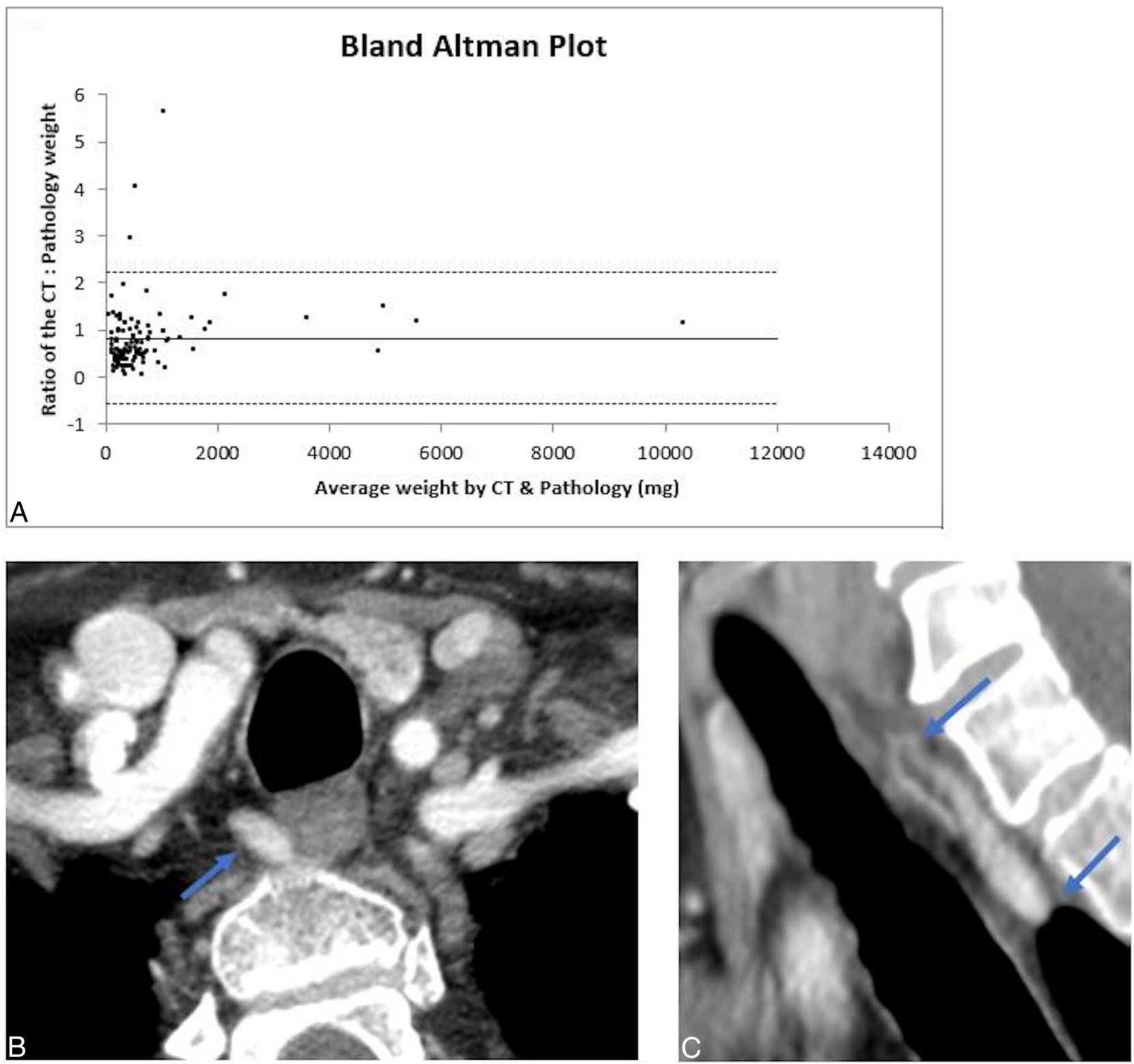

FIG 4. Correlation between Weight $\mathrm{HD}_{\mathrm{D}-\mathrm{CT}}$ and Weight $\mathrm{pathology}_{\text {. }} \mathrm{A}$, Bland-Altman plot. The solid line represents the mean ratio (0.83), and the dashed lines represent the lower and upper $95 \%$ limits of agreement at 0.56 and -2.22 , respectively. Representative imaging case of $63-y e a r-o l d$ woman with right upper parathyroid adenoma. Axial $(B)$ and Sagittal $(C)$ arterial phase images from preoperative 4D-CT demonstrate a teardropshaped right upper parathyroid adenoma in the right tracheoesophageal groove measuring $10 \times 5 \times 19 \mathrm{~mm}$ (transverse $\times$ anterior-posterior $\times$ cranio-caudal), with weight $4 \mathrm{D}-\mathrm{CT}$ of $475 \mathrm{mg}$. Weight $\mathrm{pathology}_{\text {was }} 530 \mathrm{mg}$ with CT: pathologic weight ratio of 0.90 .

(Fig 4). There was a negative systemic bias, with the CT-estimated weight underestimating the pathologic weight, with a mean ratio

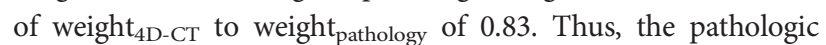
weight can be predicted by the formula:

$$
\begin{aligned}
\text { weight }_{\text {pathalogy }}(\mathrm{mg}) & =\text { weight }_{4 \mathrm{D}-\mathrm{CT}}(\mathrm{mg}) / 0.83 \\
& =1.2 \times \text { weight }_{4 \mathrm{D}-\mathrm{CT}}(\mathrm{mg})
\end{aligned}
$$

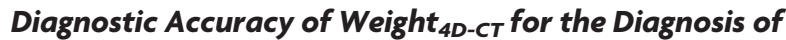 Parathyroid Adenoma}

CT-estimated weight (Fig 5) reached an AUC of 0.955 (95\% CI, $0.92-0.985 ; \quad P<.001)$ for the prediction of parathyroid adenoma. On the basis of the Youden index, a threshold weight $>50 \mathrm{mg}$ was the most optimal in discriminating between a parathyroid adenoma and normal parathyroid gland, with a sensitivity of $96.7 \%$ and a specificity of $95.7 \%$. We tested the threshold cutoff of $50 \mathrm{mg}$ in the validation set, with a similar sensitivity of $100 \%$ and a specificity of $96.6 \%$. Of note, the performance characteristics were similar across a range of thresholds from 40 to $80 \mathrm{mg}$ (Table 2). For example, a threshold of $>40 \mathrm{mg}$ had a sensitivity of $96.4 \%$ and a specificity of $92.3 \%$, a threshold of $>60 \mathrm{mg}$ had a sensitivity of $94.4 \%$ and a specificity of $96.2 \%$, and a threshold of $>80 \mathrm{mg}$ had a sensitivity of $90.0 \%$ and a specificity of $97.4 \%$. Figure 6 demonstrates a case of a patient with a small adenoma and additional identified normal glands. 


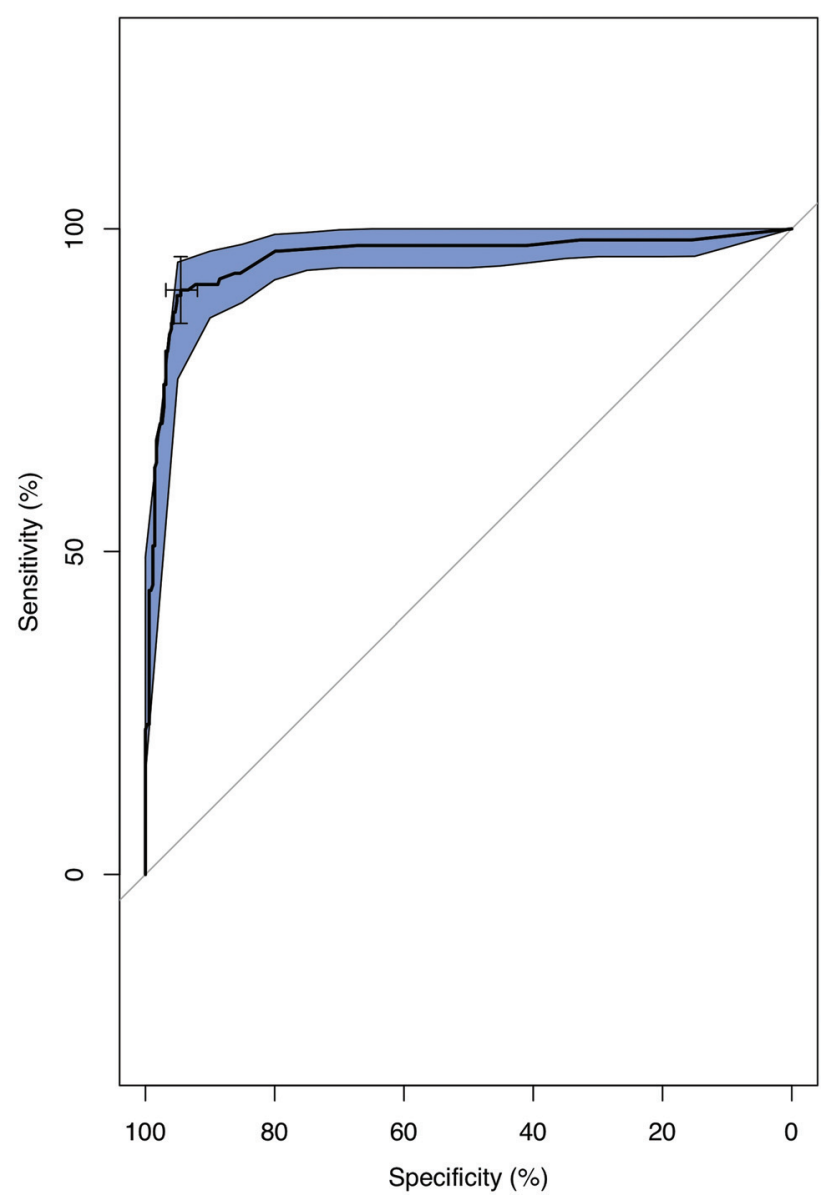

FIG 5. ROC curve showing the diagnostic performance of CT-estimated parathyroid weight in discriminating parathyroid adenoma from the normal parathyroid gland, with confidence intervals (blue) (AUC $=0.955 ; 95 \mathrm{Cl}, 0.925-0.985 ; P<.001)$.

Table 2: Performance characteristics for various CT-estimated weight thresholds

\begin{tabular}{lccc}
\hline $\begin{array}{l}\text { Weight } \\
\text { (m)-CT }\end{array}$ & $\begin{array}{c}\text { Sensitivity } \\
(\%)\end{array}$ & $\begin{array}{c}\text { Specificity } \\
(\%)\end{array}$ & $\begin{array}{c}\text { Youden } \\
\text { Index }\end{array}$ \\
\hline 40 & 96.4 & 92.3 & 0.890 \\
50 & 96.7 & 95.7 & 0.924 \\
60 & 94.4 & 96.2 & 0.906 \\
70 & 91.1 & 97.0 & 0.881 \\
80 & 90.0 & 97.4 & 0.874 \\
\hline
\end{tabular}

Using longest dimension of a parathyroid gland on CT, the AUC was 0.981 (95\% CI, 0.969-0.993) for prediction of parathyroid adenoma (On-line Figure), with an optimal threshold length of $>6.5 \mathrm{~mm}$ based on the Youden index, yielding a sensitivity of $94.8 \%$ and a specificity of $95.9 \%$.

\section{DISCUSSION}

We evaluated the use of preoperative 4D-CT in estimating parathyroid adenoma weight with a predefined formula of CTderived measurements compared with the pathologic weight in patients with primary hyperparathyroidism and solitary parathyroid adenomas. Our results showed that CT-estimated weight and pathologic weight had a strong positive correlation, moderate agreement, and excellent reliability. These findings demonstrate that 4D-CT can closely predict the parathyroid adenoma weight at resection using a simple formula. Because CT underestimates the pathologic weight by a mean ratio of 0.83 , we propose using a refined formula to predict pathologic weight: weight pathology $=$ $1.2 \mathrm{mg} / \mathrm{mm}^{3} \times \mathrm{L}(\mathrm{mm}) \times \mathrm{W}(\mathrm{mm}) \times \mathrm{H}(\mathrm{mm}) \times \pi / 6$, which can be simplified further to weight pathology $=0.63 \mathrm{mg} / \mathrm{mm}^{3} \times \mathrm{L}(\mathrm{mm})$ $\times \mathrm{W}(\mathrm{mm}) \times \mathrm{H}(\mathrm{mm})$. In clinical practice, this formula could be easily implemented using an automated calculator or Excel (Microsoft) spreadsheet and the estimated parathyroid weight reported in the radiology report. Adenoma weight is a critical factor in the surgeon's intraoperative approach and decision-making, and providing an accurate preoperative weight estimate allows the surgeon to more effectively plan the operation.

Our study also determined an optimal CT size cutoff of $>50 \mathrm{mg}$ to distinguish a parathyroid adenoma from a normal gland, with high diagnostic performance. This suggests that CT-estimated weight can be used to distinguish solitary parathyroid adenomas from normal parathyroid glands and is particularly important in localizing smaller adenomas or when differential CT contrast enhancement is equivocal or unreliable, occurring not infrequently due to poor contrast bolus timing or streak artifacts from contrast injection or the patient's shoulders. Because accurate localization of the abnormal parathyroid adenoma is critical for a minimally invasive parathyroidectomy, a low false-negative rate and thus a higher sensitivity may be more favorable to surgeons. For our refined formula, we propose a corrected CT size cutoff of $>60 \mathrm{mg}(1.2 \times 50 \mathrm{mg})$. This finding is concordant with the pathologic weight cutoff of $>60 \mathrm{mg}$ used by pathologists and surgeons ${ }^{8,10}$ and demonstrates that similar thresholds were still obtained despite using differing methodologies of preoperative CT scans and autopsy studies. In addition, the CT-estimated weights of normal glands in our study are similar to those reported in prior autopsy studies. ${ }^{16,17}$

There are several potential reasons for the slight underestimation of adenoma weight on 4D-CT. Given the location of the parathyroid glands, parathyroid adenomas are in close proximity to other anatomic structures, including the thyroid, thymus, carotid artery, jugular vein, and neck muscles, which can result in mass effect and compression of parathyroid adenomas. For example, compression of a parathyroid adenoma can be seen in cases of concomitant enlarged multinodular thyroid goiter or when parathyroid adenomas are very large and confined by adjacent structures. Second, surgical specimens may include adjacent fat and thymic gland, which may lead to a higher measured pathologic weight. Third, our method of estimating weight on CT is based on assumptions that parathyroid adenomas are ellipsoid and have a density equal to that of water. Differences in adenoma shape (teardrop, cylindric, and so forth) would, therefore, affect the CT-estimated weight. Also, the true density of parathyroid tissue is slightly greater than that of water, with density in the range of $1.049-1.069 \mathrm{mg} / \mathrm{mm} .^{3,18}$ The amount of stromal fat in 

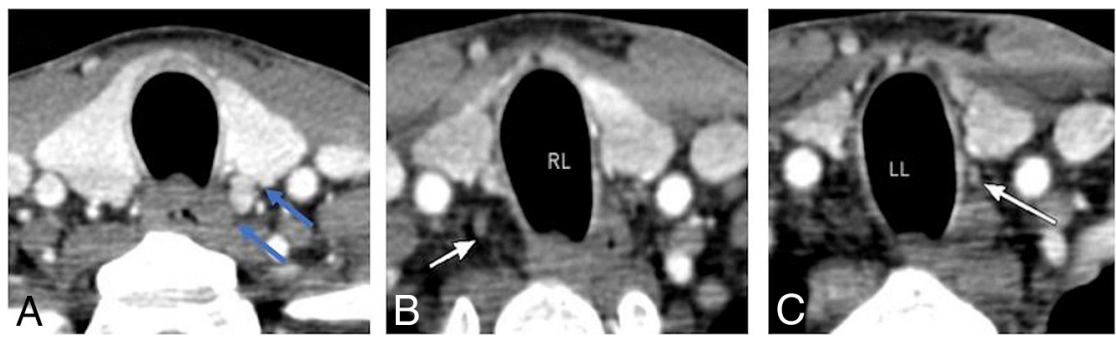

FIG 6. A 61-year-old woman with left upper parathyroid adenoma. A, Axial arterial phase CT image demonstrates a left upper parathyroid (blue arrows) with CT-estimated weight of $70 \mathrm{mg}$. Additional normal right lower $(24 \mathrm{mg})(B)$ and left lower $(18 \mathrm{mg})(C)$ parathyroid glands are identified (white arrows). RL indicates right lower; and LL, left lower.

the parathyroid gland may also affect the density of the gland. ${ }^{19}$ It is plausible that adenomatous changes in the parathyroid gland decrease the fat content and render the parathyroid adenoma denser, another factor for underestimation of the pathologic weight by CT-based weight estimates. Only 1 prior study has evaluated the correlation of CT-estimated weight and pathologic weight and showed a positive correlation with a Pearson correlation coefficient of $0.96{ }^{20}$ We also found a positive correlation with a Spearman correlation coefficient of 0.73 . The Spearman correlation was used in our study because of the skewed distribution in our dataset.

Prior studies have shown that parathyroid adenoma size can affect the localization accuracy of sestamibi, ${ }^{21,22}$ with lower accuracy in smaller glands. However, the effect of parathyroid adenoma size on the diagnostic accuracy of $4 \mathrm{D}-\mathrm{CT}$ is not as well-established, with few studies in the literature. Day et $\mathrm{al}^{23}$ evaluated $4 \mathrm{D}-\mathrm{CT}$ in patients with negative findings on sonography or sestamibi scans and found that the mean pathologic weight of glands successfully localized by $4 \mathrm{D}-\mathrm{CT}$ was $404 \mathrm{mg}$ compared with $259 \mathrm{mg}$ for those not localized by $4 \mathrm{D}-\mathrm{CT}$. Similarly, Galvin et $\mathrm{al}^{3}$ showed that the mean weight of glands missed on 4D-CT was $0.3 \mathrm{~g}$ compared with $0.6 \mathrm{~g}$ in detected glands, but there was no statistical difference $(P=.15)$. In our cohort, the mean pathologic weight of adenomas not successfully localized on 4D-CT was $136 \mathrm{mg}$; however, this estimate is based on only 4 patients. While prior studies were based on postoperative pathologic weight, our study allows extrapolation of these findings to preoperative CT-estimated weight by demonstrating a strong positive correlation between CT-estimated weight and pathologic weight. A preoperative $4 \mathrm{D}-\mathrm{CT}$ size evaluation by Sho et $\mathrm{al}^{24} \mathrm{dem}-$ onstrated that abnormal parathyroid glands missed on $4 \mathrm{D}-\mathrm{CT}$ were smaller, with mean of $8.6 \mathrm{~mm}$ versus $12.4 \mathrm{~mm}(P<.001)$, and parathyroid glands of $\geq 10 \mathrm{~mm}$ had higher chances of nonlocalization on $4 \mathrm{D}-\mathrm{CT}$ (odds ratio $=4.37$; $95 \% \mathrm{CI}, 2.24-8.54$ ). We found that a parathyroid gland length cutoff of $>6.5 \mathrm{~mm}$ for the longest dimension could potentially be used to differentiate adenomas from normal glands; however, the longest dimension may not be the most accurate measurement of parathyroid size, given the differences in parathyroid gland shape and morphology.

There are several limitations in our study. First, our CT-estimated weights were calculated assuming an ellipsoid volume and density of water. More accurate volume assessments can be with multigland disease remains to be studied.

obtained through manual CT segmentation of the adenoma; however, this method would not be ideal in standard clinical workflow. Second, we included only patients with parathyroid adenomas correctly localized by $4 \mathrm{D}-\mathrm{CT}$ with subsequent surgical cure, which may influence our results. Only 4 patients had unsuccessful localization on $4 \mathrm{D}$ $\mathrm{CT}$, and this is probably due to the high diagnostic accuracy of $4 \mathrm{D}-\mathrm{CT}$. Last, we also limited the study to include only patients with solitary parathyroid adenomas; thus, whether these results can be applied to patients

\section{CONCLUSIONS}

This study demonstrates that using a formula to estimate parathyroid adenoma weight on $4 \mathrm{D}-\mathrm{CT}$ is valid and reproducible, and a CT weight cutoff of $>50 \mathrm{mg}$ can be used to distinguish a parathyroid adenoma from normal glands. Our findings can be applied in routine clinical practice to help radiologists improve interpretation and reporting of $4 \mathrm{D}-\mathrm{CT}$ scans and guide surgeons in preoperative planning. Future directions include evaluating this formula in patients with multigland disease.

\section{REFERENCES}

1. Rodgers SE, Hunter GJ, Hamberg LM, et al. Improved preoperative planning for directed parathyroidectomy with 4-dimensional computed tomography. Surgery 2006;140:932-41 CrossRef Medline

2. Hoang JK, Sung WK, Bahl M, et al. How to perform parathyroid 4D CT: tips and traps for technique and interpretation. Radiology 2014;270:15-24 CrossRef Medline

3. Galvin L, Oldan JD, Bahl M, et al. Parathyroid 4D CT and scintigraphy: what factors contribute to missed parathyroid lesions? Otolaryngol Head Neck Surg 2016;154:847-53 CrossRef Medline

4. Starker LF, Mahajan A, Björklund P, et al. 4D parathyroid CT as the initial localization study for patients with de novo primary hyperparathyroidism. Ann Surg Oncol 2011;18:1723-28 CrossRef Medline

5. Suh YJ, Choi JY, Kim SJ, et al. Comparison of 4D CT, ultrasonography, and 99mTc sestamibi SPECT/CT in localizing single-gland primary hyperparathyroidism. Otolaryngol Head Neck Surg 2015;152:43843 CrossRef Medline

6. Yeh R, Tay YK, Tabacco G, et al. Diagnostic performance of 4D CT and sestamibi SPECT/CT in localizing parathyroid adenomas in primary hyperparathyroidism. Radiology 2019;291:469-76 CrossRef Medline

7. Bahl M, Sepahdari AR, Sosa JA, et al. Parathyroid adenomas and hyperplasia on four-dimensional CT scans: three patterns of enhancement relative to the thyroid gland justify a three-phase protocol. Radiology 2015;277:454-62 CrossRef Medline

8. Yao K, Singer FR, Roth SI, et al. Weight of normal parathyroid glands in patients with parathyroid adenomas. J Clin Endocrinol Metab 2004;89:3208-13 CrossRef Medline

9. Grimelius L, Bondeson L. Histopathological diagnosis of parathyroid diseases. Pathol Res Pract 1995;191:353-65 CrossRef Medline

10. Kunstman JW, Kirsch JD, Mahajan A, et al. Parathyroid localization and implications for clinical management. J Clin Endocrinol Metab 2013;98:902-12 CrossRef Medline 
11. Lampen-Sachar K, Zhao B, Zheng J, et al. Correlation between tumor measurement on computed tomography and resected specimen size in lung adenocarcinomas. Lung Cancer 2012;75:332-35 CrossRef Medline

12. Tann M, Sopov V, Croitoru S, et al. How accurate is helical CT volumetric assessment in renal tumors? Eur Radiol 2001;11:1435-38 CrossRef Medline

13. Bilezikian JP, Khan AA, Potts JT Jr; Third International Workshop on the Management of Asymptomatic Primary Hyperthyroidism. Guidelines for the management of asymptomatic primary hyperparathyroidism: summary statement from the third international workshop. J Clin Endocrinol Metab 2009;94:335-39 CrossRef Medline

14. Richards ML, Thompson GB, Farley DR, et al. An optimal algorithm for intraoperative parathyroid hormone monitoring. Arch Surg 2011;146:280-85 CrossRef Medline

15. Lin LI. A concordance correlation coefficient to evaluate reproducibility. Biometrics 1989;45:255-68 Medline

16. Akerström G, Grimelius L, Johansson H, et al. The parenchymal cell mass in normal human parathyroid glands. Acta Pathol Microbiol Scand A 1981;89:367-75 CrossRef Medline

17. Gilmour JR, Martin WJ. The weight of the parathyroid glands. $J$ Pathol Bacteriol 1937;44:431-62 CrossRef

18. Wang CA, Rieder SV. A density test for the intraoperative differentiation of parathyroid hyperplasia from neoplasia. Ann Surg 1978;187:6367 CrossRef Medline
19. Roth SI, Gallagher MJ. The rapid identification of "normal" parathyroid glands by the presence of intracellular fat. Am J Pathol 1976;84:521-28 Medline

20. Stucken EZ, Kutler DI, Moquete R, et al. Localization of small parathyroid adenomas using modified 4-dimensional computed tomography/ultrasound. Otolaryngol Head Neck Surg 2012;146:33-39 CrossRef Medline

21. Nichols KJ, Tronco GG, Palestro CJ. Influence of multigland parathyroid disease on 99mTc-sestamibi SPECT/CT. Clinl Nucl Med 2016;41:282-88 CrossRef Medline

22. Tay YD, Yeh R, Kuo JH, et al. Pre-operative localization of abnormal parathyroid tissue by $(99 \mathrm{~m}) \mathrm{Tc}$-sestamibi in primary hyperparathyroidism using four-quadrant site analysis: an evaluation of the predictive value of vitamin D deficiency. Endocrine 2018;60:3645 CrossRef Medline

23. Day KM, Elsayed M, Beland MD, et al. The utility of 4-dimensional computed tomography for preoperative localization of primary hyperparathyroidism in patients not localized by sestamibi or ultrasonography. Surgery 2015;157:534-39 CrossRef Medline

24. Sho S, Yuen AD, Yeh MW, et al. Factors associated with discordance between preoperative parathyroid 4-dimensional computed tomographic scans and intraoperative findings during parathyroidectomy. JAMA Surg 2017;152:1141-47 CrossRef Medline 